\title{
Ocular Graft Versus Host Disease
}

National Cancer Institute

\section{Source}

National Cancer Institute. Ocular Graft Versus Host Disease. NCI Thesaurus. Code C158730.

Graft versus host disease occurring in the eye. 